\title{
Infants' detection of increments in low- and high-frequency noise
}

\author{
KATHLEEN M. BERG and AMY E. BOSWELL \\ University of Florida, Gainesville, Florida
}

\begin{abstract}
A visually reinforced operant paradigm was employed to examine the relationship between the difference limen (DL) for intensity and level of the standard during infancy. In Experiment 1, 7-month-old infants and adults detected increments in continuous noise presented via headphones at each of four levels ranging from 28 to $58 \mathrm{~dB}$ SPL. Noise stimuli were 2-octave bands centered at either 400 or $4000 \mathrm{~Hz}$, and increments were 10 and $100 \mathrm{msec}$ in duration. Infants' DLs were significantly larger than those of adult subjects and significantly larger for low- than for high-frequency stimuli. For the highfrequency noise band, infants' DLs were generally consistent with Weber's law, remaining essentially constant for standards higher than $28 \mathrm{~dB}$ SPL ( $3 \mathrm{~dB} \mathrm{SL}$ ) for 100-msec increments and $38 \mathrm{~dB}$ SPL (13 dB SL) for 10-msec increments. For low-frequency noise, infants' absolute thresholds were exceptionally high, and sensation levels of the standards were too low to adequately describe the relationship. In Experiment 2, 7-month-old infants detected 10- and 100-msec increments in 400-Hz noise stimuli presented in sound field. Infants' low-frequency DLs were large at low intensities and decreased with increases in level of the standard up to at least $30 \mathrm{~dB}$ SL. For both low- and high-frequency noise, the difference between DLs for 10- and 100-msec increments tended to be large at low levels of the standard and to decrease at higher levels. These results suggest that the relationship between the DL and level of the standard varies with both stimulus frequency and duration during infancy. However, stimulusdependent immaturities in increment detection may be most evident at levels within approximately $30 \mathrm{~dB}$ of absolute threshold.
\end{abstract}

One of the most basic of auditory capacities is the ability to detect a change in the intensity or level of an auditory stimulus. This ability has been widely studied in both normal and hearing-impaired adults, but little is known about discrimination of intensity differences in infants and young children. The few experiments examining this topic from a developmental perspective are consistent in showing poorer performance in young subjects. Sinnott and Aslin (1985) reported difference limens (DLs) ranging from 3 to $12 \mathrm{~dB}$ for a group of 7- to 9 -month-old infants detecting increments in a constantly repeating 1$\mathrm{kHz}$ tone presented at $60 \mathrm{~dB}$ SPL. By comparison, adult DLs obtained under identical conditions ranged from 1 to $2 \mathrm{~dB}$. Bull, Eilers, and Oller (1984) varied the intensity of individual synthetic syllables embedded within multisyllable wordlike units and found increment thresholds on the order of 2-6 dB in young infants; Schneider and Trehub (1985) reported similar estimates of 2.5-5 dB for infants' detection of increments in continuous broadband noise. These values compare with DLs of less than $1 \mathrm{~dB}$ typically obtained in adult subjects for similar types of stimuli (see, e.g., Miller, 1947). Both Jensen and Neff (1993) and Maxon and Hochberg (1982) examined DLs

This research was supported in part by NIDCD Grant DC 00017 and by the National Organization for Hearing Research. The helpful comments of Mary Florentine and two anonymous reviewers are gratefully acknowledged. Correspondence should be addressed to K. M. Berg, IASCP, 63 Dauer Hall, University of Florida, Gainesville, FL 326117425 (e-mail: kmberg@cpd.ufl.edu). for repeated tones in slightly older subjects. Their data indicate that the ability to discriminate differences in intensity continues to improve well into childhood.

Perhaps the most frequently studied aspect of intensity discrimination is the relationship between the DL and level of the standard. The rule commonly used to describe this relationship is Weber's law, which states that the justdetectable change in a stimulus is a constant proportion of its initial intensity. For discrimination of differences in auditory intensity, Weber's law provides only an approximate description of the data. At low levels of the standard, performance deviates from Weber's law because detection is limited by absolute threshold. For tones and band-limited stimuli presented in quiet, deviations from Weber's law are also seen at high levels, a result that has been termed the near miss (McGill \& Goldberg, 1968). Current views attribute the near miss to the nonlinear spread of neural excitation along the cochlear partition as intensity increases (Florentine \& Buus, 1981). When stimuli are broadband noise or tones presented in notched noise to restrict the spread of excitation, Weber's law appears to hold for standard levels ranging from approximately 10 to $20 \mathrm{~dB}$ above threshold to levels exceeding $100 \mathrm{~dB}$ SPL (Miller, 1947; Viemeister, 1988). ${ }^{1}$

Of the studies investigating intensity discrimination during infancy, only Schneider and Trehub (1985) examined performance at more than one level of the standard. They reported that the DL for detection of increments in broadband noise was not constant, but decreased from approximately 5 to $2.5 \mathrm{~dB}$ as level of the background in- 
creased from 40 to $60 \mathrm{~dB}$ SPL. This suggests that discrimination performance may not be consistent with Weber's law early in development. The present investigation was designed to address this question by examining infants' ability to detect differences in intensity over a wider range of standard levels. Because previous work has demonstrated that the thresholds of 6-to 7-month-old infants are significantly less mature at low than at mid and high frequencies (Olsho, Koch, Carter, Halpin, \& Spetner, 1988; Trehub, Schneider, \& Endman, 1980), we elected to compare discrimination performance for both low- and highfrequency noise bands. Under a number of conditions, thresholds are also less mature at short durations during infancy. For noise stimuli presented in quiet, infants' temporal-summation functions are significantly steeper than those of adults (Berg, 1991; Berg \& Boswell, 1995). To determine whether infants' temporal-summation functions would also be excessively steep for discrimination of differences in intensity, thresholds were examined for intensity increments both 10 and $100 \mathrm{msec}$ in duration.

Several different paradigms have been used to study intensity discrimination in adult subjects. In one type of experiment, two sounds are presented in sequence and subjects judge which of the two is more intense. In a second type, the listener's task is to detect an increment in the level of a continuous sound. Except at very low levels of the standard, DLs are found to be consistently smaller in increment-detection than in burst-comparison paradigms (Viemeister, 1988). The reason for this difference is not completely understood, although both differential memory requirements and adaptation to the standard have been advanced as possible explanations (Turner, Zwislocki, \& Filion, 1989). Burst comparison is the procedure most commonly used in the adult literature. However, an increment-detection task was used in the present study in an effort to minimize cognitive demands on young subjects. As pointed out by Miller (1947), increment detection can be considered as a special case of masking in which the signal (increment) and masker (standard) are identical in frequency, phase, and bandwidth. One goal of the present study was to describe the relationship between infants' increment thresholds and level of the standard for noise stimuli of different frequencies and durations. A second goal was to examine temporal summation in level discrimination during infancy.

\section{EXPERIMENT 1}

\footnotetext{
Method

Subjects. Eighty infants and 40 young adults served as subjects. Infants were tested when 29 to 34 weeks of age (mean age = 31.7 weeks). All were reported by their parents to be in good health and free of colds or ear infections on test days. Sixty-seven additional infants were seen in the laboratory but excluded from the final sample due to fussiness or loss of interest in visual reinforcers (46), failure to meet training criteria (14), refusal to wear headphones (6), and equipment problems (1).
}

Adult subjects were undergraduate students recruited from introductory psychology courses who received class credit for their participation.

Stimuli. Bands of filtered noise, 2 octaves in width and centered at either 400 or $4000 \mathrm{~Hz}$, were generated by passing the output of a white-noise generator (Brüel \& Kjaer 1405) through low- and highpass sections of a Rockland 816 analog filter (Butterworth, $48 \mathrm{~dB} /$ oct rolloff). The filter output was divided into two channels. One channel provided the continuous standard; the other was passed through a cosine switch (TDT SW1) and programmable attenuator (TDT PA3) and added back to the first in phase to produce an intensity increment. Increments were gated with a rise/decay time of $5 \mathrm{msec}$ and durations of 10 and $100 \mathrm{msec}$ as measured at half-power points. The continuous standard was presented at 4 levels selected to be well above adult threshold but not uncomfortably loud. Spectrum levels ranged from 0 to $30 \mathrm{~dB} / \mathrm{Hz}$ for low, and from -10 to $20 \mathrm{~dB} / \mathrm{Hz}$ for high-frequency noise bands. These correspond to standard levels of $28,38,48$, and $58 \mathrm{~dB}$ SPL for both low- and high-frequency conditions.

Noise increments were presented in trains consisting of up to seven repetitions per trial. Onset-to-onset interval of individual bursts was $600 \mathrm{msec}$, resulting in a train approximately $4 \mathrm{sec}$ in duration. All stimuli were delivered to the subject's left ear via a pair of lightweight circumaural headphones (Sony MDR-CD6) held in place by an elastic headband.

Procedure. Testing was conducted using the visually reinforced operant procedure we have employed previously (e.g., Berg \& Boswell, 1995). Infants were seated on their parent's lap in the center of a sound-treated chamber, with a loudspeaker and three animated toys in Plexiglas boxes located $90^{\circ}$ to the left. An experimenter seated directly in front of the infant manipulated quiet toys to direct his/her attention to midline and initiated trials when head position and state were judged appropriate. A second experimenter outside the chamber observed the infant through one-way glass and made judgments on head turns. Both wore headphones and received a signal marking the observation interval on each trial, but did not hear stimuli delivered to the infant.

The test procedure employed a single-interval go/no-go paradigm in which signal and nonsignal trials occurred with equal probability. They were presented in random order with the restriction that no more than three trials of either type be presented consecutively. ${ }^{2}$ Trials were initiated at random intervals and only when the infant was in a state best described as "mildly interested" in the objects displayed at midline. If the infant turned to the left during an observation interval, the experimenter outside the chamber pressed a button to record the response and terminate the interval. Observation intervals not terminated by a response were $4 \mathrm{sec}$ in duration. Head turns to the left on signal trials were considered correct detections and were immediately reinforced by the 3 -sec activation of an animated toy. Turns during nonsignal trials were recorded as false alarms and were not reinforced. If the infant became obviously distracted during an observation interval, the trial was rejected.

Subjects were randomly assigned to groups, each consisting of 8 infants, and received both 10 - and 100 -msec increments for a single noise band and level of the standard. Order of duration conditions was counterbalanced across subjects within each group. In addition, 10- and 100-msec, low- and high-frequency noise stimuli were presented in quiet, resulting in a total of 10 groups. Sessions began with a training phase in which $100-\mathrm{msec}$ noise bursts were presented over the loudspeaker at a clearly audible level. After four consecutive correct turns to the left, headphones were applied, and training continued until a criterion of three additional consecutive turns had been met. For subjects assigned to receive short-duration increments first, burst duration was reduced to $10 \mathrm{msec}$ and training continued until three consecutive turns had been obtained in re- 
sponse to the assigned test stimulus. During the course of the experiment, it became clear that a disproportionate number of infants assigned to low-frequency conditions failed to meet training criteria. As a result, procedures for subjects receiving low-frequency noise were altered to include initial training with wide-band noise stimuli prior to introduction of the filtered noise bursts. This extended training sequence was followed for 33 of the 40 infants in lowfrequency groups.

Once training criteria had been met, an adaptive one-up, twodown tracking procedure was initiated. Increment level was initially set $35-45 \mathrm{~dB}$ [in terms of $20 \log (\Delta \mathrm{P} / \mathrm{P})$, where $\mathrm{P}$ is sound pressure] above comparable adult threshold for low-frequency conditions and 25-30 dB above adult threshold for high-frequency conditions. Step size began at $8 \mathrm{~dB}$ and decreased by half on subsequent updown reversals until a minimum step size of $2 \mathrm{~dB}$ had been reached. Only outcomes on signal trials contributed to alterations in the level of the increment. After the first reversal, probe trials with the increment set $10 \mathrm{~dB}$ above the current tracking level were presented every eighth trial to provide an estimate of distraction or loss of interest in the reinforcers. Tracking was terminated after five reversals, and an estimate of threshold increment level was computed as the mean level in the increment channel over the last three reversals. This was converted to increment power $(\Delta \mathrm{I})$, taking into account the in-phase addition of standard and increment waveforms. Thresholds were considered acceptable if (1) false alarms occurred on no more than one third of the nonsignal trials, (2) the infant failed to respond on no more than two probe trials, and (3) the excursion of the staircase was less than $10 \mathrm{~dB}$ after the third reversal. Within a session, testing continued either until threshold estimates meeting the above criteria had been obtained for both duration conditions or until the infant's state precluded further testing. Parents of infants successfully tested on only a single condition during their initial visit to the laboratory were asked to return for a second session. For both low- and high-frequency noise bands, approximately $30 \%$ of threshold estimates did not meet the criteria for acceptance. Chi- square tests indicated that the incidence of rejected thresholds did not differ across experimental conditions.

Adult subjects were tested using procedures that duplicated the infant test situation as closely as possible. They were seated alone in the chamber, provided with a response box, and instructed to press a button whenever they heard the stimulus train. Observation intervals were unmarked, and intervals between trials varied randomly between 1 and $15 \mathrm{sec}$. Lights within one of the Plexiglas boxes were flashed briefly as feedback for correct detections. Adult subjects received both low- and high-frequency noise bands at a single level of the standard. All other procedures were identical to those described for infants.

\section{Results}

Absolute thresholds for 10- and 100-msec noise bursts, together with increment thresholds obtained for each level of the standard, are shown for both low- and highfrequency stimuli in Figure 1. Plotted in this way, the data can be interpreted as masking functions in which the threshold intensity of the signal (increment) is shown for various levels of the continuous masker (standard). Prior to statistical analysis, all data were screened for homogeneity of variance using Levene's test. For instances in which group variances were not homogeneous, the significance of differences between experimental conditions was assessed using the Brown-Forsythe statistic (Dixon, Brown, Engelman, \& Jennrich, 1990), which compensates for the effect of unequal variances by reducing the degrees of freedom. Because adults received both lowand high-frequency noise stimuli but infants were tested under only a single frequency condition, error terms for age comparisons involving signal frequency were com-

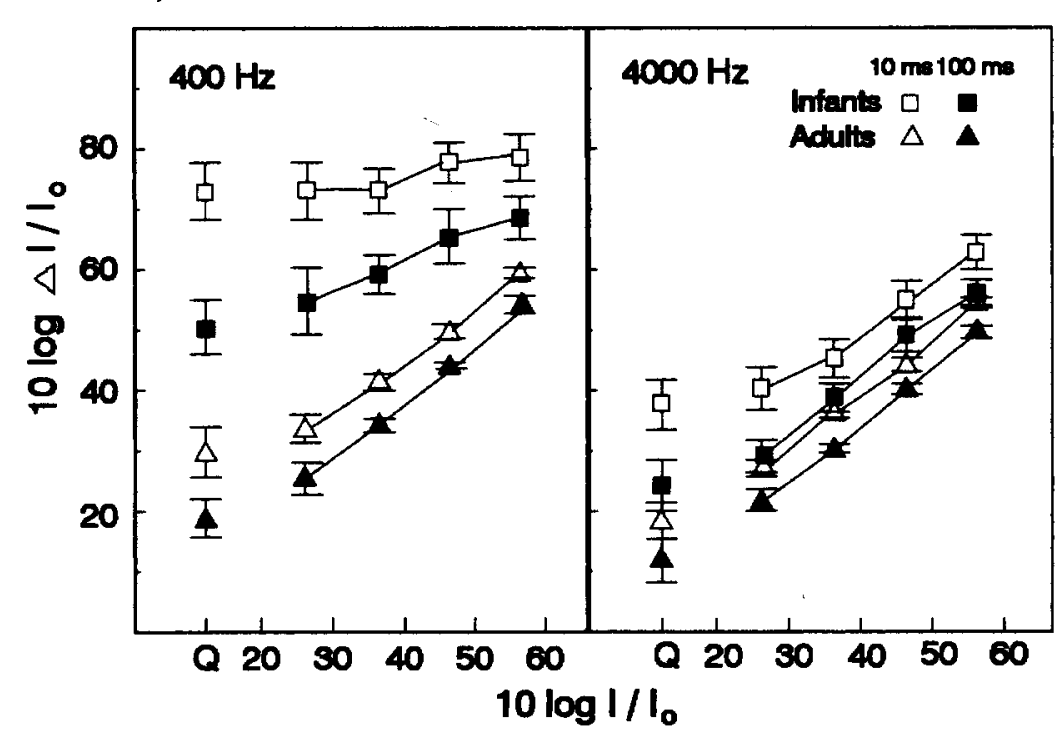

Figure 1. Mean infant and adult thresholds for detection of 10- and 100-msec increments in 2-octave bands of continuous noise presented at each of four levels. Noise bands were centered at 400 and $4000 \mathrm{~Hz}$. Values plotted at points labeled "Q" are absolute thresholds for 10- and 100-msec noise bursts. Error bars represent $\pm 1 S D$ from the mean. 
puted separately for the two age groups and then pooled (Winer, 1971, pp. 371-384).

Infants' thresholds for 4-kHz stimuli presented in quiet were in good agreement with results from previous work, but absolute thresholds for the $400-\mathrm{Hz}$ noise bursts were higher than expected. Since effects of leakage in the seal between the earphone cushion and pinna are more pronounced at low frequencies (Zwislocki et al., 1988), it is possible that acoustic leakage may have been a factor. Nevertheless, the general pattern of results was similar to findings previously reported for similar stimuli (Berg, 1991; Berg \& Boswell, 1995; Trehub et al., 1980). Infants' thresholds were less mature for low- than for highfrequency noise, and less mature for shorter than for longer duration bursts at both low and high frequencies. For 100-msec stimuli, infants' absolute thresholds averaged $12 \mathrm{~dB}$ above adults' for high-frequency noise and $31 \mathrm{~dB}$ above adults' for low-frequency noise. When duration of the noise bursts was $10 \mathrm{msec}$, comparable infant-adult differences increased to 19 and $43 \mathrm{~dB}$ for high- and lowfrequency noise bands, respectively. An analysis of variance (ANOVA) indicated that these differences were highly significant [age $\times$ frequency, $F(1,21)=92.05$, $p<.001$; age $\times$ duration, $F(1,21)=33.41, p<.001]$.

The same pattern was also evident in the masking functions for increment thresholds. As level of the standard increased from 28 to $58 \mathrm{~dB}$ SPL, adult increment thresholds, expressed in terms of increment power, increased by approximately $30 \mathrm{~dB}$, as expected. Infant thresholds increased by a similar amount for $100-\mathrm{msec}$ increments in high-frequency noise, but increases were notably smaller for all other stimulus conditions. This was especially true for $10-\mathrm{msec}$ increments in low-frequency noise, where infants' thresholds were exceptionally high and increased by only $5.5 \mathrm{~dB}$ over the $30-\mathrm{dB}$ range of the standard. For adult subjects, slopes of linear regression lines fit to these functions were generally consistent with the unity slope predicted by Weber's law. Infants' slopes were also close to 1.0 for detection of $100-\mathrm{msec}$ increments in highfrequency noise, but not for the remaining conditions. An ANOVA in thresholds for infant subjects alone confirmed that infants' slopes were more shallow for lowthan for high-frequency noise [frequency $\times$ level, $F(3,56)$ $=20.33, p<.001]$, and more shallow for 10 - than for $100-$ msec increments [duration $\times$ level, $F(3,56)=12.37, p<$ $.001]$.

Temporal summation, measured as the difference between thresholds for 10- and 100-msec increments, was significantly greater in infants than adults for both low[age $\times$ duration, $F(1,35)=118.42, p<.001]$ and highfrequency noise bands [age $\times$ duration, $F(1,32)=14.82$, $p<.001]$. Temporal summation decreased with increasing level in both age groups, but the trend was more marked for infant subjects [for $400-\mathrm{Hz}$ noise, age $\times$ level $\times$ duration, $F(3,35)=3.09, p<.05$; for $4-\mathrm{kHz}$ noise, age $\times$ level $\times$ duration, $F(3,32)=2.96, p<.05$ ].

Figure 2 shows DLs represented in terms of the level difference, $\Delta \mathrm{L}[=10 \log ((\mathrm{I}+\Delta \mathrm{I}) / \mathrm{I})]$, between the standard and standard plus increment. Although absolute thresholds of the continuous standards were not actually measured, they would be expected to differ from the threshold of a 100-msec noise burst by only approximately $3 \mathrm{~dB}$ (Thurlow \& Bowman, 1957). Thus, sensation levels (SLs) of the standards can be estimated from the group mean thresholds for $100-\mathrm{msec}$ noise bursts in quiet. For adult subjects, SLs of the standard estimated in this way ranged from approximately 15 to $45 \mathrm{~dB} \mathrm{SL}$ for the high-frequency noise band, and from 9 to $39 \mathrm{~dB}$ SL for low-frequency

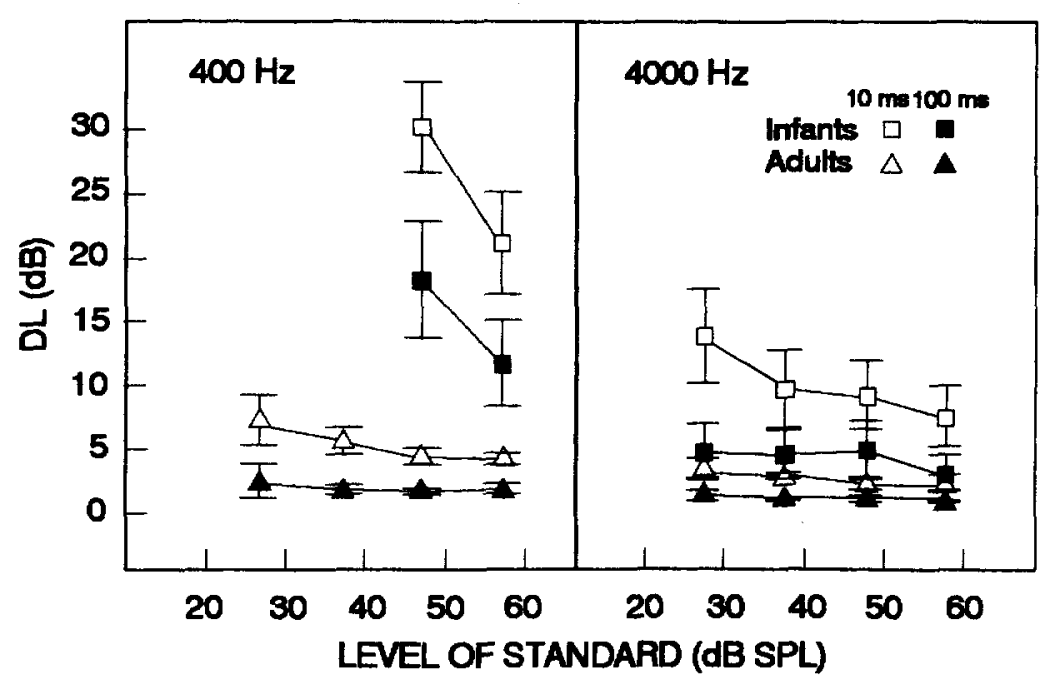

Figure 2. Mean infant and adult difference limens, represented in terms of $\Delta L$ $[10 \log ((I+\Delta I) / I)]$ for 10 - and 100-msec increments in 2-octave bands of continuous noise presented at each of four levels. Noise bands were centered at 400 and $4000 \mathrm{~Hz}$. Error bars represent $\pm 1 S D$ from the mean. 
noise. Comparable levels estimated for infant listeners ranged from 3 to $33 \mathrm{~dB}$ SL for high-frequency noise. Because infants' thresholds for low-frequency noise bursts in quiet were exceptionally high, two levels of the lowfrequency standard were below threshold, a third was "near threshold," and only the highest level standard was clearly above threshold at $8 \mathrm{~dB}$ SL. Infant data obtained for the 28 and $38 \mathrm{~dB}$ SPL low-frequency standards have therefore been omitted from the figure.

For both noise bands and durations, adult DLs tended to decrease slightly over the lowest levels of the standard, but then remained constant over higher levels in accordance with Weber's law. Post hoc tests using Scheffé multiple-comparison procedure indicated that there were no significant differences among adult DLs obtained for the three highest levels of the standard under any of the four stimulus conditions. Mean DLs, averaged over these three levels, were 4.7 and $1.7 \mathrm{~dB}$ for 10 - and 100 -msec increments in low-frequency noise, and 2.4 and $0.9 \mathrm{~dB}$ for $10-$ and $100-\mathrm{msec}$ increments in high-frequency noise. These values are well within the range of level differences previously reported for adult subjects under similar experimental conditions (Miller, 1947; Small, Bacon, \& Fozard, 1959; Viemeister, 1988).

Since 28 and $38 \mathrm{~dB}$ SPL low-frequency standards were clearly below threshold for infant listeners, the results for infants receiving low-frequency noise do not permit a description of the relationship between the DL and level of the standard. However, when infant and adult DLs for low-frequency noise are compared at approximately equal sensation levels (standard $=28 \mathrm{~dB}$ SPL for adults and $58 \mathrm{~dB}$ SPL for infants), it is clear that infants' performance remained considerably poorer for 100 -msec increments (DL $=11.6 \mathrm{~dB}$ for infants vs. $2.3 \mathrm{~dB}$ for adults) and that age differences were even greater for $10-\mathrm{msec}$ increments $(\mathrm{DL}=21.1 \mathrm{~dB}$ for infants vs. $7.3 \mathrm{~dB}$ for adults.)

Infants' performance was more adultlike for highfrequency noise, although the main effect of age was still highly significant $(p<.001)$. Post hoc comparisons indicated that for $10-\mathrm{msec}$ increments, performance improved significantly as the standard increased from 28 to $38 \mathrm{~dB}$ SPL, but then remained constant with further increases in level. Mean DL, averaged over the three highest levels of the standard, was $8.6 \mathrm{~dB}$. For detection of 100 -msec increments, infants' DLs did not differ over the three lowest levels of the standard (mean $\mathrm{DL}=4.6 \mathrm{~dB}$ ). Mean DL obtained for the $58 \mathrm{~dB}$ SPL standard (DL = $2.8 \mathrm{~dB}$ ) was significantly smaller than mean $\mathrm{DL}$ for the $48 \mathrm{~dB}$ SPL standard $(p<.05)$, but was not reliably different from DLs obtained at the two lower levels, suggesting that this apparent improvement in performance may have been due to chance. However, it is worth noting that the same trend was reported by Schneider and Trehub (1985) for infants' detection of increments in broadband noise. An ANOVA of data obtained at the three highest standard levels confirmed that infants' DLs for high- frequency noise, like those for low-frequency stimuli, were significantly less mature at the shorter duration [age $\times$ duration, $F(1,12)=40.03, p<.001$ ]

Analysis of responses on nonsignal trials indicated that false alarm rates were significantly higher in infants than adults $[M=.19$ vs. $.06, F(1,140)=135.97, p<.001]$. For infant subjects, false alarms also occurred more frequently for low- than for high-frequency noise bands $[m=.21$ vs $.17, F(1,70)=8.35, p<.01]$, but did not differ across levels or durations. ${ }^{3}$

\section{EXPERIMENT 2}

In an effort to determine why infants' absolute thresholds for low-frequency noise bursts were so much higher than those previously reported in the literature, a group of eight 7-month-olds was tested using the same $400-\mathrm{Hz}$ noise band presented in sound field. For these subjects, mean threshold for $100-\mathrm{msec}$ noise bursts in quiet was $30.4 \mathrm{~dB}$ SPL $(S D=4.9 \mathrm{~dB})$, nearly $20 \mathrm{~dB}$ lower than thresholds obtained for the same stimuli presented via headphones in Experiment 1, and very close to soundfield thresholds reported by Trehub et al. (1980) for 400$\mathrm{Hz}$ octave-band noise bursts. We therefore used soundfield presentation to determine noise-increment thresholds in two additional groups of infants for continuous standards of 50 and $60 \mathrm{~dB}$ SPL, or approximately 20 and $30 \mathrm{~dB}$ SL.

\section{Method}

Subjects. Eight 7-month-old infants were tested at each of two levels of the continuous standard. Ages ranged from 29 to 34 weeks (mean age $=32.2$ weeks). Ten additional infants were tested but excluded from the final sample due to failure to meet training criteria (3) or loss of interest in the visual reinforcers before testing could be completed (7).

Procedure. Procedures were identical to those of the previous experiment except that the $400-\mathrm{Hz}$ noise stimuli were delivered through a Bose Model 100 loudspeaker located adjacent to the visual reinforcers. To eliminate possible sources of bias, both the parent and the experimenter seated in the chamber with the infant received masking stimuli via headphones throughout the session.

\section{Results}

Figure 3 shows infants' DLs for $400-\mathrm{Hz}$ stimuli presented in sound field, along with comparable adult DLs for low-frequency noise from Experiment 1. Infant data shown at the lowest standard level are those obtained for the $58 \mathrm{~dB}$ SPL standard in the previous experiment. In all cases, sensation levels of the standard were estimated from group mean absolute thresholds for noise bursts $100 \mathrm{msec}$ in duration. These data indicate that for lowfrequency stimuli, infants' discrimination performance continued to improve with increasing level of the standard up to at least $30 \mathrm{~dB}$ SL. As level of the standard increased from 20 to $30 \mathrm{~dB} \mathrm{SL}$, infants' DLs decreased from 10.2 to $6.6 \mathrm{~dB}$ for $10-\mathrm{msec}$ increments, and from 4.8 to $3.7 \mathrm{~dB}$ for $100-\mathrm{msec}$ increments. An ANOVA of DLs obtained in Experiment 2 confirmed that this im- 


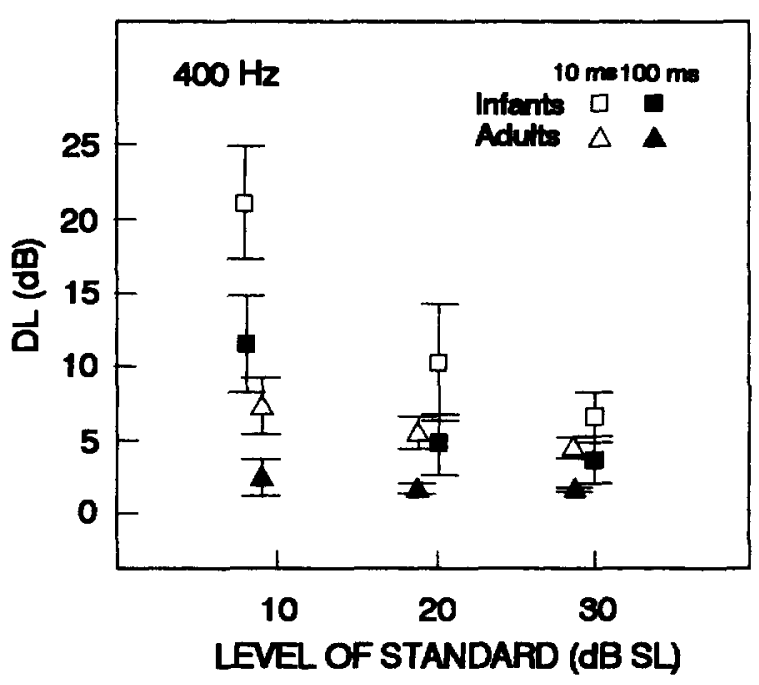

Figure 3. Mean infant and adult difference limens for 10 - and 100 -msec increments in a 2-octave band of continuous noise centered at $400 \mathrm{~Hz}$, plotted as a function of sensation level of the standard. Difference limens are represented in terms of $\Delta L[10$ log $((I+\Delta I / I)]$. Infant data for 20 and $30 \mathrm{~dB}$ SL standards were obtained in sound field. Adult DLs and infant data shown at the lowest level of the standard are from the previous experiment and were obtained using headphones. Error bars represent $\pm 1 S D$ from the mean.

provement in performance was statistically significant [level, $F(1,14)=5.75, p<.05]$ and significantly greater for 10- than for $100-\mathrm{msec}$ increments [level $\times$ duration, $F(1,14)=5.89, p<.05]$. When level of the standard was approximately $30 \mathrm{~dB}$ SL, infants' DLs remained significantly larger than those of adult subjects [age, $F(1,8)=$ $44.20, p<.001]$, but age differences were equivalent for both 10- and 100-msec increments (age $\times$ duration, $F<$ 1). Adult and infant DLs for the $30 \mathrm{~dB}$ SL standard were also compared with DLs obtained for the high-frequency standard of approximately the same SL ( $33 \mathrm{~dB}$ SL for infants, $35 \mathrm{~dB}$ SL for adults) in Experiment 1. For detection of increments $100 \mathrm{msec}$ in duration, age differences were comparable for low- and high-frequency noise bands (age $\times$ frequency, $F<1$ ). This was not the case for detection of 10-msec increments, where infants' performance was significantly less mature at high than at low frequencies [age $\times$ frequency, $F(1,16)=8.82, p<.01$ ]. Mean false alarm rate for the infants tested in sound field was .19 . As in Experiment 1, the incidence of false alarms did not differ across experimental conditions.

\section{DISCUSSION}

The ability of young infants to detect increments in continuous, band-limited noise was examined in two experiments. In general, the results were consistent with the findings from previous investigations reporting poorer discrimination performance in young listeners: Infants' DLs were significantly larger than adults' for both lowand high-frequency noise bands and for increments both
10 and $100 \mathrm{msec}$ in duration. One question of interest was whether increment thresholds would remain constant with increases in initial level, as predicted by Weber's law. When the results of Experiments 1 and 2 are considered together, it is possible to compare infants' DLs for lowand high-frequency stimuli for standard levels ranging from near threshold to approximately $30 \mathrm{~dB}$ SL. Our findings suggest that over this range of intensities, the relationship between the DL and level of the standard varies with both stimulus frequency and duration during infancy. Infants' performance was most consistent with Weber's law for high-frequency noise. Although infants' highfrequency DLs were significantly larger than those of adult subjects, they remained essentially constant for standards higher than $28 \mathrm{~dB}$ SPL ( $3 \mathrm{~dB}$ SL) for $100-\mathrm{msec}$ increments and $38 \mathrm{~dB}$ SPL (13 dB SL) for 10-msec increments. By comparison, infants' DLs for low-frequency noise were exceptionally large at low levels of the standard and decreased with increasing intensity. In Experiment 1, standard SLs were lower than intended due to infants' high absolute thresholds for low-frequency noise bursts. In Experiment 2, infants' low-frequency DLs were found to decrease with increases in level of the standard up to at least $30 \mathrm{~dB} \mathrm{SL}$, and this decrease was significantly greater for 10- than for 100-msec increments. For adult subjects tested over a comparable range of SLs, DLs either remained constant (100-msec increments) or decreased only slightly ( $10-\mathrm{msec}$ increments). As a result, age differences were equivalent for detection of 10 - and $100-\mathrm{msec}$ increments in low-frequency noise when level of the standard was $30 \mathrm{~dB}$ SL. Furthermore, age differences were also equivalent for low- and high-frequency DLs when level of the standard was approximately $30 \mathrm{~dB}$ SL and increments were $100 \mathrm{msec}$ in duration.

It is widely recognized that much of the difference between infant and adult performance on psychoacoustic tasks can be attributed to nonauditory factors such as attention and listening strategies (see, e.g., Werner \& Marean, 1996). Although nonsensory variables undoubtedly contributed to age differences in the present study, the different trends observed for infants' detection of increments in $400-$ and $4000-\mathrm{Hz}$ noise argue that there are also differences in the coding of intensity at low and high frequencies during infancy. If one assumes, as do many current models of intensity discrimination, that performance is based on detection of a change in excitation within the auditory system, then infants' poorer performance at $400 \mathrm{~Hz}$ may reflect either a slower rate of growth of excitation with increasing intensity or a greater variability of excitation. The rapid improvement in infants' low-frequency DLs with increasing intensity suggests that such frequency-specific differences are most evident at levels within approximately $30 \mathrm{~dB}$ of absolute threshold.

A second question of interest in the present study concerned the effect of increment duration on discrimination of differences in level. It is generally agreed that the improvement in level discrimination with increasing duration seen in adult listeners is not consistent with "true" 
integration of increment energy (Florentine, 1986; Green, Nachmias, Kearney, \& Jeffress, 1979). Not only is the rate of improvement more gradual than predicted on the basis of energy integration, but also critical durations are considerably longer than "integration times" commonly reported for stimuli presented in quiet (Florentine, 1986). An alternative hypothesis based on the concepts of signal detection theory proposes that discrimination performance is limited by an internal noise process whose variance decreases in proportion to the stimulus duration. Thus, $d^{\prime}$ should increase in proportion to the square root of the stimulus duration (Scharf \& Buus, 1986). When increment threshold is expressed in terms of $\Delta \mathrm{L}$, the predicted relationship between the DL and increment duration is described by a straight line with a slope of -.5 on a double-logarithmic plot (Florentine, 1986). This is fairly close to slopes obtained for adult subjects in the present study: Mean adult slope, averaged over both lowand high-frequency conditions, was -.44 . However, for infant listeners, the difference between DLs for 10- and $100-\mathrm{msec}$ increments tended to be large at low levels of the standard and to decrease with increasing intensity at both low and high frequencies. This pattern is very similar to results obtained for infants' temporal integration of low-frequency tones in increasing levels of masking noise (Berg \& Boswell, 1997). Thus, despite the different characteristics of temporal integration in detection and level discrimination paradigms, developmental trends appear to be the same for the two tasks. Florentine (1986; Buus \& Florentine, 1992) has argued that the -.5 slope predicted by signal detection theory should obtain only if the amount of information per unit time remains constant throughout the duration of the stimulus. Therefore, it seems possible that the steeper slopes seen in young infants may reflect a reduction in the amount of information available at stimulus onset. The finding that infants' temporal-integration functions become less steep at higher levels of the standard suggests that the representation of stimulus onsets may become more adultlike with increasing intensity. For infants tested with low-frequency noise in sound field, temporal summation of level discrimination was not significantly different from that of adults when level of the standard was $30 \mathrm{~dB}$ SL. This was not the case for high-frequency noise, although group comparisons are limited by the differences in procedures.

\section{REFERENCES}

BERG, K. M. (1991). Auditory temporal summation in infants and adults: Effects of stimulus bandwidth and masking noise. Perception \& Psychophysics, 50, 314-320.

BERG, K. M., \& Boswell, A. E. (1995). Temporal summation of 500$\mathrm{Hz}$ tones and octave-band noise bursts in infants and adults. Perception \& Psychophysics, 57, 183-190.

BERG, K. M., \& BOSWELL, A. E. (1997). Effect of masker level on infants detection of tones in noise. Manuscript submitted for publication.

Bull, D., Eilers, R., \& Oller, D. K. (1984). Infants' discrimination of intensity variation in multisyllabic stimuli. Journal of the Acoustical Society of America, 76, 13-17.

BuUs, S., \& Florentine, M. (1992). Possible relation of auditory nerve adaptation to slow improvement in level discrimination with increas- ing duration. In Y. Cazals, L. Demany, \& K. Horner (Eds.), Auditory physiology and perception (pp. 279-288). New York: Pergamon.

BuUs, S., \& Florentine, M. (1995). Sensitivity to excitation-level differences within a fixed number of channels as a function of level and frequency. In G. A. Manley, G. M. Klump, C. Koppl, H. Fastl, \& $\mathrm{H}$. Oeckinghaus (Eds.), Advances in hearing research (pp. 401-414). Singapore: World Scientific

CARlyon, R., \& MOORE, B. C. J. (1984). Intensity discrimination: A severe departure from Weber's law. Journal of the Acoustical Society of America, 76, 1369-1375.

Carlyon, R., \& Moore, B. C. J. (1986). Continuous versus gated pedestals and the "severe departure" from Weber's law. Journal of the Acoustical Society of America, 79, 453-460.

Dixon, W., Brown, M., Engelman, L., \& JenNRich, R. (1990). BMDP statistical software manual. Berkeley: University of California Press.

FLORENTINE, M. (1986). Level discrimination of tones as a function of duration. Journal of the Acoustical Society of America, 79, 792-798.

Florentine, M., \& BuUs, S. (1981). An excitation-pattern model for intensity discrimination. Journal of the Acoustical Society of America, 70, 1646-1654.

Florentine, M., BuUs, S., \& MASON, C. (1987). Level discrimination as a function of level for tones from 0.25 to $16 \mathrm{kHz}$. Journal of the Acoustical Society of America, 81, 1528-1541.

Green, D. M., Nachmias, J., Kearney, J., \& Jefrress, L. (1979). Intensity discrimination with gated and continuous sinusoids. Journal of the Acoustical Society of America, 66, 1051-1056.

JENSEN, J., \& NEFF, D. (1993). Development of basic auditory discrimination in preschool children. Psychological Science, 4, 104-107.

MAXON, A., \& Hochberg, I. (1982). Development of psychoacoustic behavior: Sensitivity and discrimination. Ear \& Hearing, 3, 301-308.

MCGiLL, W. J., \& GolDBERG, J. P. (1968). A study of the near-miss involving Weber's law and pure-tone intensity discrimination. Perception \& Psychophysics, 4, 105-109.

MILLER, G. (1947). Sensitivity to changes in the intensity of white noise and its relation to masking and loudness. Journal of the Acoustical Society of America, 19, 609-619.

Olsho, L. W., Koch, E., Carter, E., Halpin, C., \& Spetner, N. (1988). Pure-tone sensitivity of human infants. Journal of the Acoustical Society of America, 84, 1316-1324.

SCHARF, B., \& BuUs, S. (1986). Audition I. Stimulus, physiology, thresholds. In K. R. Boff, L. Kaufman, \& J. P. Thomas (Eds.), Handbook of perception and human performance (pp. 14.1-14.71). New York: Wiley.

SCHNEIDER, B. \& TREHUB, S. (1985). Behavioral assessment of basic auditory abilities. In S. E. Trehub \& B. Schneider (Eds.), Auditory development in infancy (pp. 101-114). New York: Plenum.

SinNotT, J., \& Aslin, R. (1985). Frequency and intensity discrimination in human infants and adults. Journal of the Acoustical Society of America, 78, 1986-1992.

Small, A., Bacon, W. E., \& Fozard, J. (1959). Intensive differential thresholds for octave-band noise. Journal of the Acoustical Society of America, 31, 508-510.

Thurlow, W. R., \& Bowman, R. (1957). Threshold for thermal noise as a function of duration and interruption rate. Journal of the Acoustical Society of America, 29, 281-283.

Trehub, S., Schneider, B., \& Endman, M. (1980). Developmental changes in infants' sensitivity to octave-band noises. Journal of Experimental Child Psychology, 29, 282-293.

Turner, C. W., ZWISLOCKI, J., \& Filion, P. (1989). Intensity discrimination determined with two paradigms in normal and hearing-impaired subjects. Journal of the Acoustical Society of America, 86, 109-115.

VIEMEISTER, N. (1988). Psychophysical aspects of auditory intensity coding. In G. Edelman, W. E. Gall, \& W. M. Cowan (Eds.), Auditory function: Neurobiological bases of hearing (pp. 213-241). New York: Wiley.

Werner, L. A., \& Marean, G. C. (1996). Human auditory development. Boulder, CO: Westview Press.

WINER, B. J. (1971). Statistical principles in experimental design. New York: McGraw-Hill.

ZWislocki, J., Kruger, B., Miller, J., Niemoeller, A., Shaw, E. \& STUDEBAKER, G. (1988). Earphones in audiometry. Journal of the Acoustical Society of America, 83, $1688-1689$. 


\section{NOTES}

1. Exceptions to this generalization have been reported for high-frequency tones. When stimuli are tones between 6 and $10 \mathrm{kHz}$, discrimination performance is frequently worse at intermediate levels of the standard than at either lower or higher levels (Buus \& Florentine, 1995; Carlyon \& Moore, 1984, 1986; Florentine, Buus, \& Mason, 1987).

2 . Because observation intervals were unmarked and trials were presented at random intervals, trial sequences were not apparent to subjects. Adult experimenters were not explicitly provided with trial information, but could infer hits and false alarms from consequences of the infant's behavior. Due to the restriction on trial sequences, information regarding trial type was available to adult experimenters on a very small percentage of trials. With the inclusion of probe trials, trial type was predictable immediately following either four hits or three false alarms on consecutive trials. These sequences of events occurred very infrequently

3 . The use of a tracking algorithm in which changes in level were based only upon outcomes on signal trials served to minimize the effect of false alarms on estimated threshold. Computer simulations indicated that as false alarm rate increased from 0 to the maximum accepted rate of .33 , estimated threshold decreased by approximately $2.5 \mathrm{~dB}$. For the mean false alarm rate of .19 obtained for infant subjects in the present experiment, the decrease in computed threshold was less than $1.5 \mathrm{~dB}$.

(Manuscript received February 16, 1996; revision accepted for publication September 24, 1997.) 